\title{
Heart Failure with Preserved Ejection Fraction: a Pharmacotherapeutic Update
}

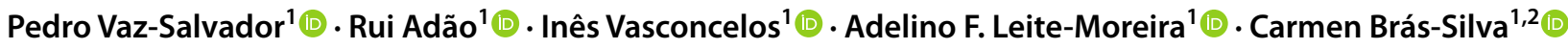

Accepted: 17 December 2021

(c) The Author(s), under exclusive licence to Springer Science+Business Media, LLC, part of Springer Nature 2021

\begin{abstract}
While guidelines for management of heart failure with reduced ejection fraction (HFrEF) are consensual and have led to improved survival, treatment options for heart failure with preserved ejection fraction (HFpEF) remain limited and aim primarily for symptom relief and improvement of quality of life. Due to the shortage of therapeutic options, several drugs have been investigated in multiple clinical trials. The majority of these trials have reported disappointing results and have suggested that HFpEF might not be as simply described by ejection fraction as previously though. In fact, HFpEF is a complex clinical syndrome with various comorbidities and overlapping distinct phenotypes that could benefit from personalized therapeutic approaches. This review summarizes the results from the most recent phase III clinical trials for HFpEF and the most promising drugs arising from phase II trials as well as the various challenges that are currently holding back the development of new pharmacotherapeutic options for these patients.
\end{abstract}

Keywords Heart failure $\cdot$ Preserved ejection fraction $\cdot$ Pharmacotherapy $\cdot$ Clinical trials

\section{Introduction}

Although initially believed to be less severe than heart failure with reduced ejection fraction (HFrEF), studies show that heart failure with preserved ejection fraction (HFpEF) prevalence has increased and accounts for as much as $50 \%$ of heart failure (HF) cases [1]. With an increasing incidence and prevalence of the comorbidities closely related

Carmen Brás-Silva

carmensb@med.up.pt

Pedro Vaz-Salvador

pedro.salvador.98@outlook.com

Rui Adão

ruiadao@med.up.pt

Inês Vasconcelos

inesfvasconcelos@gmail.com

Adelino F. Leite-Moreira

a.f.leitemoreira@gmail.com

1 Department of Surgery and Physiology, Faculty of Medicine, Cardiovascular Research and Development Center - UnIC, University of Porto, Alameda Prof. Hernâni Monteiro, 4200-319 Porto, Portugal

2 Faculty of Nutrition and Food Sciences, University of Porto, Rua Do Campo Alegre, 823 4150-180 Porto, Portugal to HFpEF, such as hypertension [2], coronary artery disease [3], obesity [4], diabetes mellitus [5], chronic obstructive pulmonary disease [6], and chronic kidney disease [7], it is expected that the prevalence of HFpEF will further escalate. The recent SARS-CoV-2 pandemic has also shown to have some association with HFpEF by either causing, unmasking, or exacerbating existing HFpEF [8] and could overall contribute to the increasing prevalence of this clinical syndrome. Furthermore, in addition to the increasing number of patients, it is expected that hospitalization and mortality will increase its economic burden in the world's health services. The global economic burden of HF has been estimated at US\$108 billion per annum [9] with the most significant costs deriving from patient hospitalization [10]. A comprehensive systematic review recently conducted by Clark et al. found that HFpEF hospitalizations represent about $60 \%$ of total HF hospitalization costs and that the high prevalence of comorbidities in this patient population further aggravates its economic burden [11]. Despite its increasing prevalence and economic burden, treatment options for HFpEF are limited, and because patients are often elderly, highly symptomatic and have decreased quality of life, the aim of therapy is primarily symptom relief and improvement of quality of life $[12,13]$. Diuretics are often used to improve congestion if present. However, therapy usually prescribed to treat 
other cardiovascular comorbidities (such as beta-blockers, mineralocorticoid receptor antagonists, angiotensin receptor blockers, or angiotensin-converting enzyme inhibitors) has lacking or inconsistent evidence on the improvement of symptoms or reduction of mortality in HFpEF [13]. As this pathology has a relatively high morbimortality [13], there is an urgent need for effective therapies.

Several pathophysiologic mechanisms lead to increased left ventricle (LV) end-diastolic pressure, causing HF symptoms [14]. Diastolic dysfunction in HFpEF patients results primarily from myocardial stiffness, a process largely regulated by the extracellular matrix, by both its composition and structure $[15,16]$, and cardiomyocytes, through the prolongation of $\mathrm{Ca}^{2+}$ transients [17, 18]. Moreover, various studies have found that alterations in titin are involved in the increased passive stiffness of the failing myocardium [19-21]. The strong association of HFpEF with chronic comorbidities also underlies a pathophysiological paradigm based on increased proinflammatory state and microvascular endothelial dysfunction contributing to impaired myocardial relaxation and compliance [22].

In recent years, several drugs have undergone phase II and phase III clinical trials for their potential as a novel pharmacological option for patients with HFpEF (Tables 1 and 2). A great percentage of these studies reported either disappointing results or no results at all. For the purposes of this review, we will explore the most recent findings from phase III clinical trials for HFpEF patients and the drugs that upon phase II trials showed most promising results as well as the various challenges that are currently holding back the development of new pharmacotherapeutic options for these patients.

\section{Current Therapeutical Challenges}

Despite recent developments in HFpEF pharmacological options, there still are no therapies proven to reduce mortality in this cohort of patients. This contrasts with HFrEF, for which there is panoply of pharmacological weapons in our arsenal, with some of the "big ones" (such as sacubitrilvalsartan, or LCZ696) being recent discoveries [23].

One of the main possible arguments for some trials' disappointing results is that HFpEF might not be as simply described as previously thought-just by the ejection fraction (EF); it is a complex syndrome with associated comorbidities and overlapping different phenotypes. In turn, this pushes us to think that, maybe, it is not the drugs that are ineffective, but it is the enormous heterogeneity of the patient population that predisposes the clinical trials to disappointing results [24]. Several post hoc analyses of the recent sacubitril-valsartan PARAGON trial (NCT01920711) point in this exact direction-despite the trial's failure to meet its primary endpoint of reducing the number of composite events of cardiovascular death and total hospitalizations related to HF [25], there are studies showing significant results comparing either other relevant endpoints or other patient subgroups from the trial. For example, regarding the timing when the drug is given after a hospitalization, it seems that there is an amplification in the relative and absolute benefits of sacubitril-valsartan compared to only valsartan when the drug is administered early after hospitalization [26]. Also, when we compare the drug's effect across the EF spectrum, we see a clear trend towards the reduction of it's effect in preventing first HF hospitalization or cardiovascular death as the EF increases [27]. Moreover, in women, the drug is effective at higher EF than in men [27]. All this shows that not only can we plan the therapy based on $\mathrm{EF}$, but also based on the comorbidities and characteristics of each patient.

The regular empirical use of beta-blockers for HFpEF is a good example of why there was a need to create more specific subgroups regarding the EF of the patients. There are only two clinical trials that studied the effects of betablockers in HFpEF patients: the SENIORS trial [28] and the J-DHF trial [29]. Regarding the first, although the results looked promising when using an EF cutoff of $>35 \%$, in post hoc analysis, the subgroup with $\mathrm{EF}>50 \%$ showed no benefits [30]. It must be said, as a sidebar, that as these trials were not designed to study the effects of beta-blockers specifically in the HFpEF population, therefore these results cannot lead to definitive and strong conclusions about the effects of betablockers in this population. This example is one of the many that led the European Society of Cardiology to create a new HF subgroup in 2016-heart failure with mid-range ejection fraction, in which the EF ranges between 40 and 50\% [13]. This subgroup includes 14\% of all HF patients [31], with an overlap of HFrEF and HFpEF phenotypes, but showing more similarities to the HFpEF subgroup [32]. This allows us to better design trials and guidelines and to better tailor each patient's therapy.

\section{Main Pharmacological Therapies}

\section{Renin-Angiotensin-Aldosterone System Inhibitors}

\section{Angiotensin Receptor-Neprilysin Inhibitor}

Sacubitril-valsartan has just become the first drug to be indicated by the Food and Drug Association for the treatment of HFpEF. As mentioned before, the PARAGON trial showed a narrow miss in achieving its primary endpoint (risk ratio $0.87,95 \% \mathrm{CI} 0.75-1.01, p=0.06$ ) and showed significant protective results for the subgroup of patients with an EF below 57\% (risk ratio 0.78, 95\% CI 


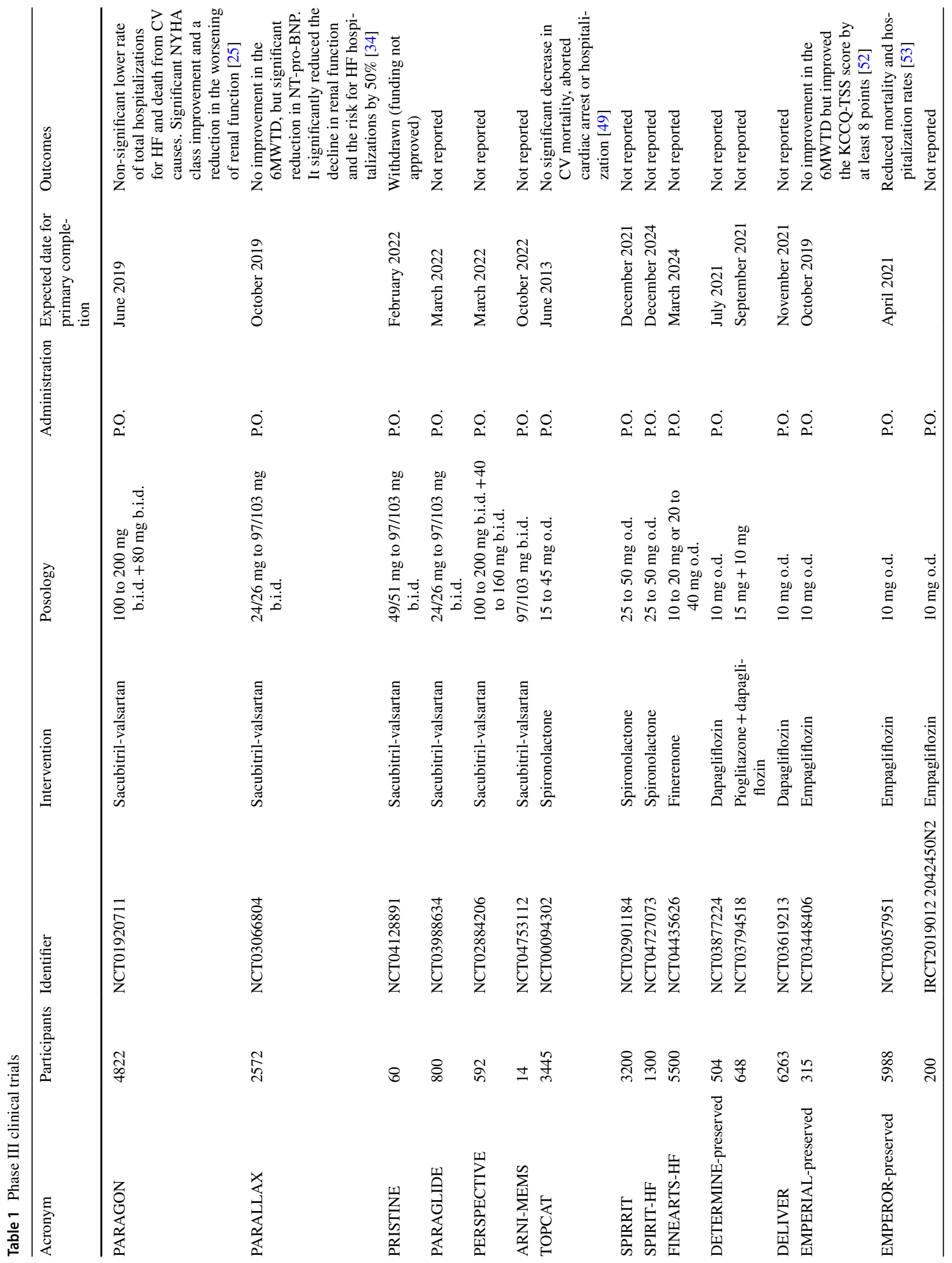




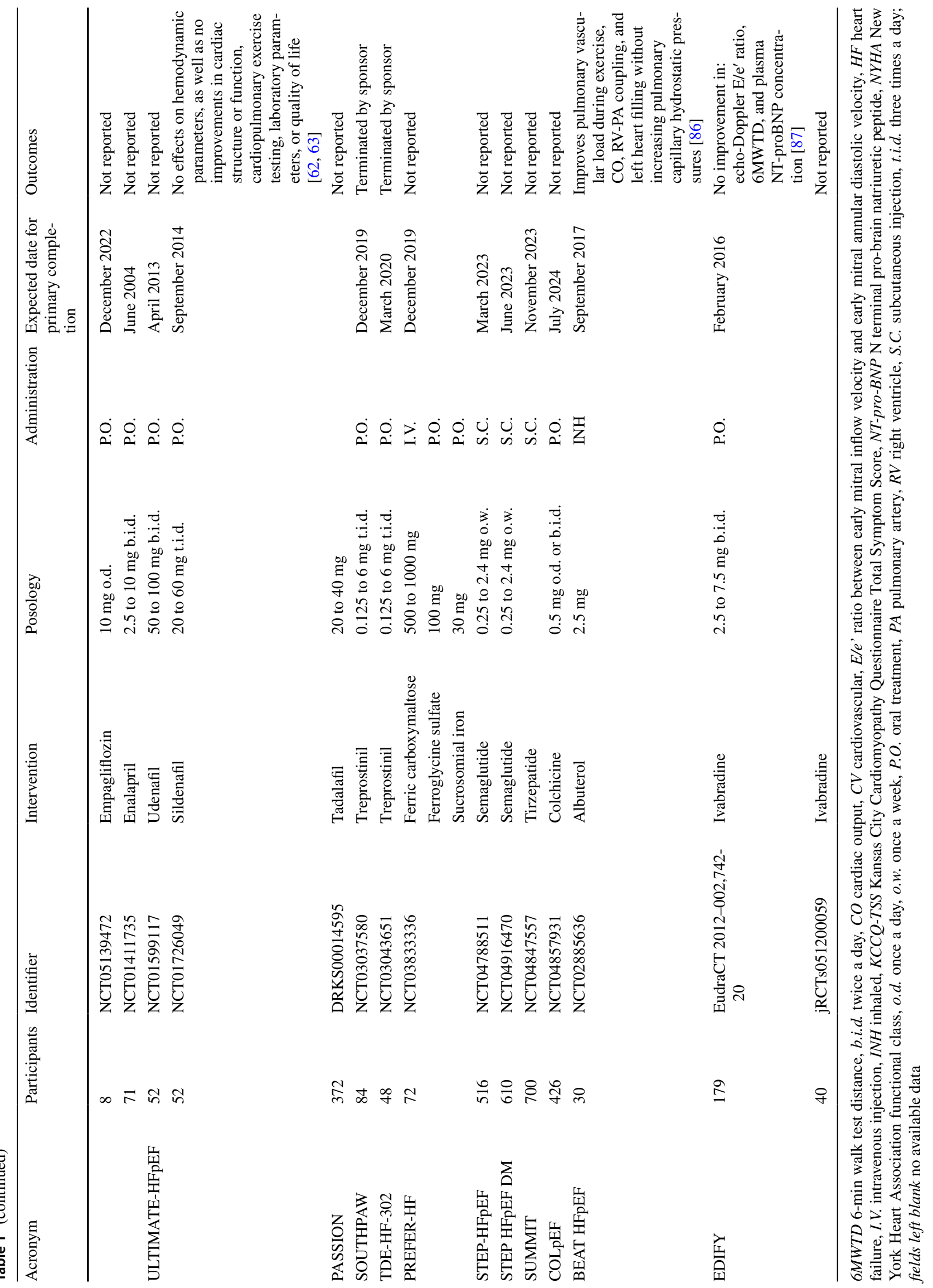




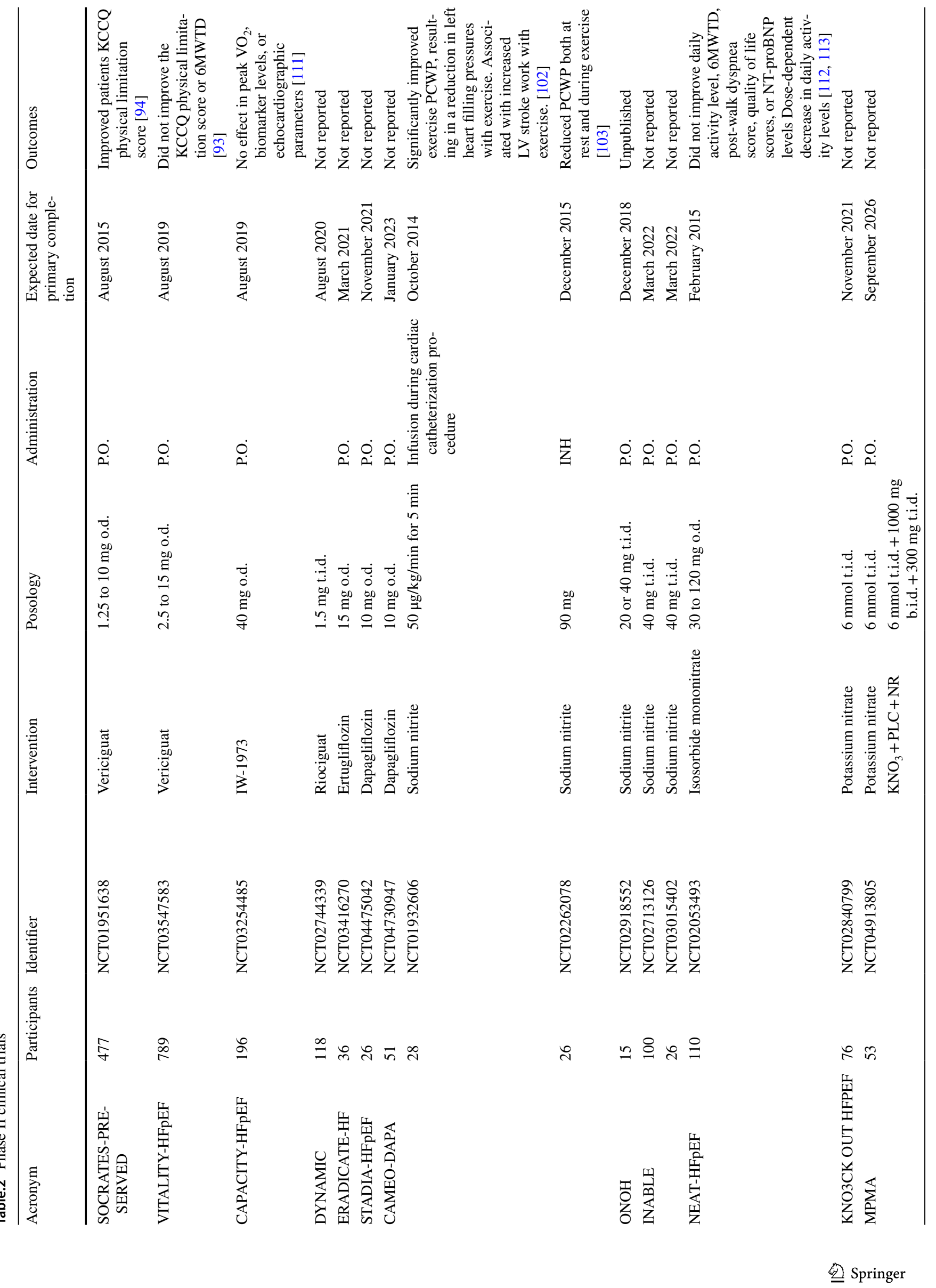




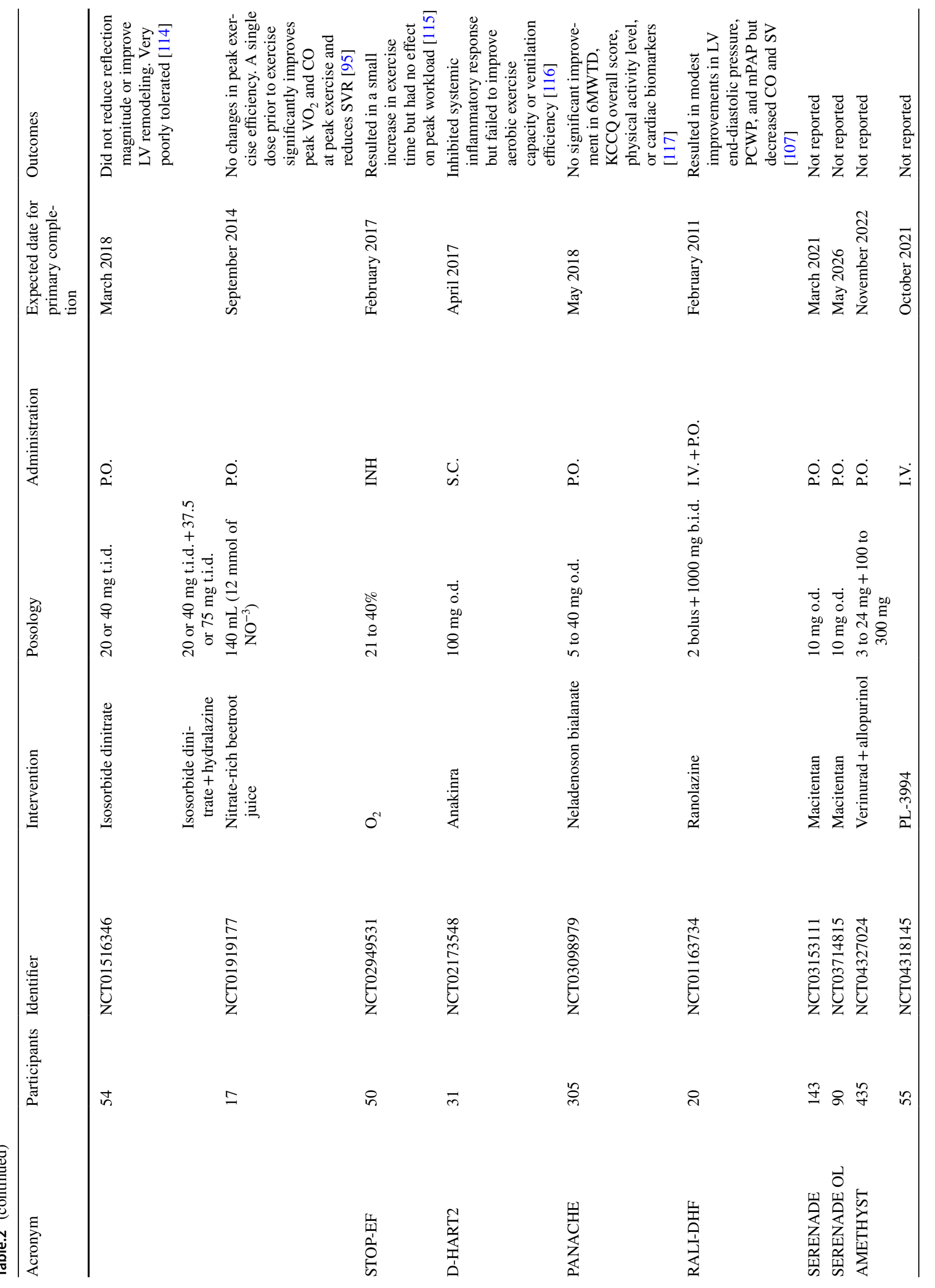




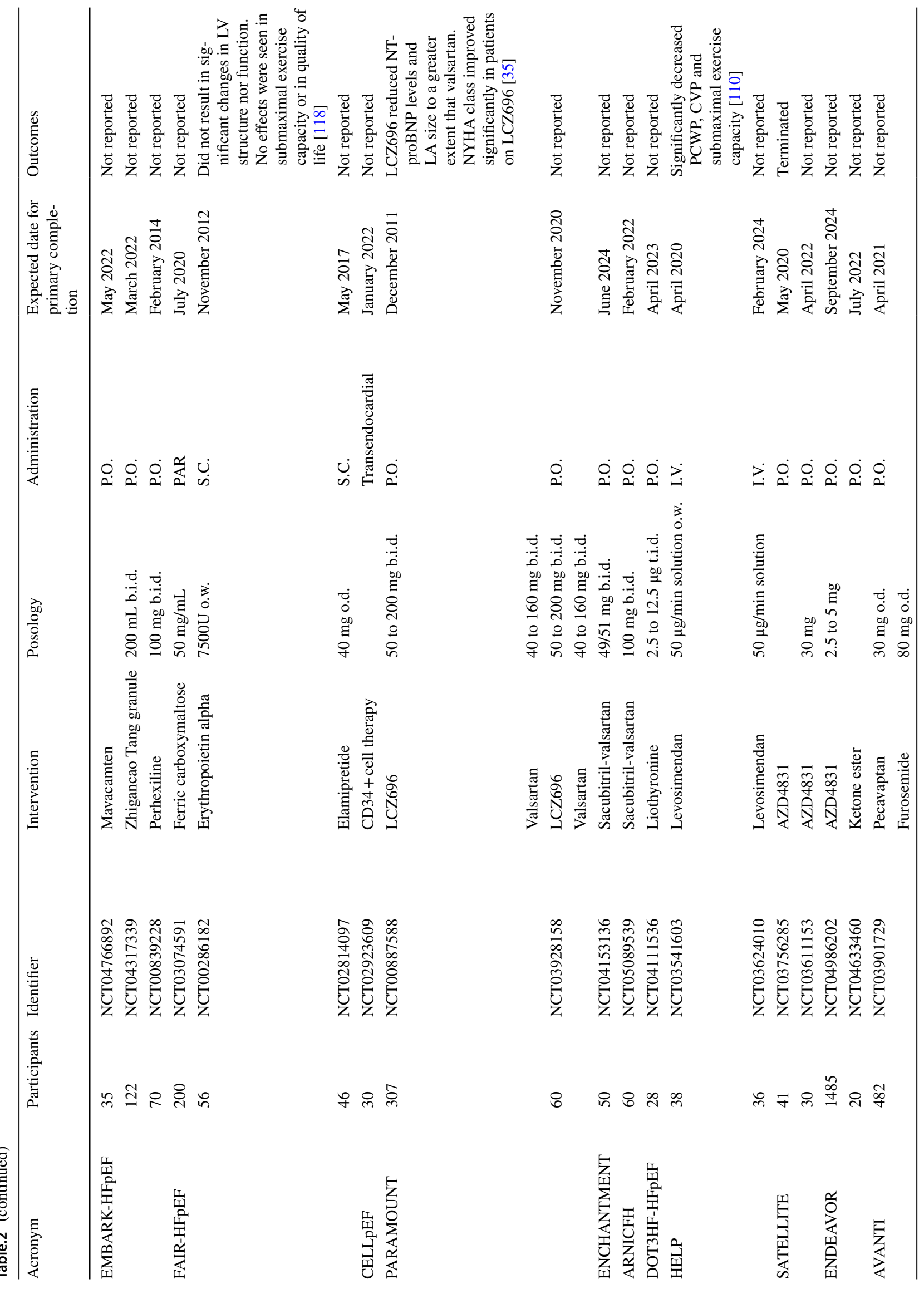




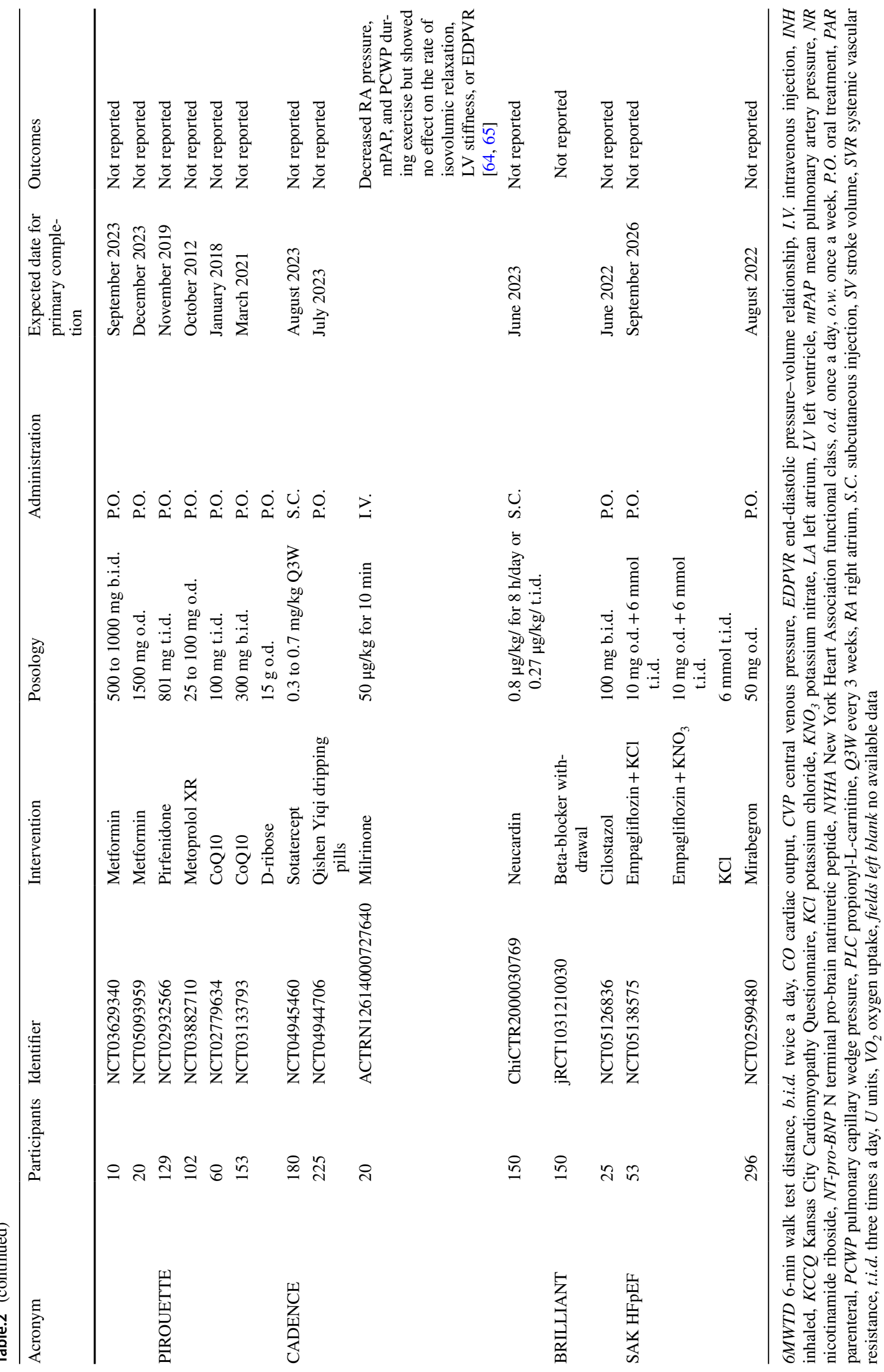


(0.64-0.95)) [25]. Some authors argue that these results do not point towards the effectiveness of sacubitril-valsartan in HFpEF, but towards a need for change in the cutoffs between HFrEF and HFpEF, as this trial showed its best results in the "best EF for HFrEF"/ "worst EF for HFpEF" subgroups [33]. The treatment also showed better benefit in women (risk ratio $0.73,95 \%$ CI (0.59-0.90)), who represent a high proportion of patients with HFpEF, than in men (risk ratio $1.03,95 \% \mathrm{CI}(0.85-1.25)$ ). Secondary outcomes in the PARAGON trial were defined as the change in the clinical summary score on the Kansas City Cardiomyopathy Questionnaire (KCCQ), change in New York Heart Association (NYHA) functional class, first occurrence of a decline in renal function, and death from any cause. Sacubitril-valsartan showed significant benefits in changes in patients' NYHA functional class and renal function, when compared to valsartan alone. During randomized treatment, sacubitril-valsartan was associated with higher incidence of hypotension and angioedema but with lower incidence of elevated serum creatinine and potassium levels than valsartan [25].

The PARALLAX clinical trial (NCT03066804) studied the effects of sacubitril-valsartan versus optimal individualized background therapy, which could be either an angiotensin II receptor blocker, an angiotensin-converting enzyme inhibitor, or a placebo [34]. This trial showed a significant reduction of NT-pro-BNP levels after 12 weeks of treatment; however, it failed to show improvement in the 6-min walk test distance (6MWTD). Furthermore, the results included a significant decrease in renal function worsening and a reduced risk for HF hospitalization by 50\% [34]. The patients enrolled in this study were selected by having a KCCQ score lower than 75, showing an impacted quality of life; however, after 24 weeks of treatment, there were no differences in the KCCQ score [34].

There are several more phase III trials currently happening (or finished but still without published results).

The PRISTINE-HF trial (NCT04128891) enrolled 60 patients. It has a primary endpoint of showing differences in the microvascular function and in cardiac ischemia, with more clinical secondary endpoints (such as changes in the NYHA functional class, differences in the 6MWTD, cardiac mortality, and HF-related hospitalizations).

The PARAGLIDE-HF trial (NCT03988634) focuses on showing differences in the NT-pro-BNP levels in the group treated with sacubitril-valsartan, compared to patients only taking valsartan.

The PERSPECTIVE trial's (NCT02884206) objective is to show differences in the cognitive function of patients with HFpEF treated with sacubitril-valsartan, using the CogState Global Cognitive Composite Score as an indicator of cognitive function and comparing with HFpEF patients taking only valsartan.
Recently, 14 patients with HFpEF and pulmonary hypertension $(\mathrm{PH})$, taking sacubitril-valsartan and implanted with an CardioMEMS HF System-a device implanted in the pulmonary artery which continuously measures the mean pulmonary artery pressure (mPAP), offering real-time data on this parameter-were enrolled in the ARNIMEMS clinical trial (NCT04753112), which aims to enlighten us on the real-time effects of this drug on mPAP, blood biomarkers, and both functionality and quality of life of the patients.

As is evident by the current existence of phase III clinical trials, phase II trials for sacubitril-valsartan showed remarkably promising results. The PARAMOUNT (NCT00887588) trial showed significant reduction in NT-proBNP blood concentration when comparing the use of sacubitril-valsartan with valsartan-only treated patients, as well as reduction in the left atrium size and greater improvement in the patients NYHA functional class [35]. Thus, this trial provided us with the preliminary results for the efficacy and the safety of the drug in patients with HFpEF.

Moreover, there is an ongoing phase II clinical trial, ENCHANTMENT-HIV (NCT04153136), evaluating whether this medication could be useful to reduce HIVrelated HFpEF, in patients between 40 and 70 years old with controlled HIV. Overall, this study aims to investigate the effect of sacubitril-valsartan on measures of heart disease related to inflammation, structure, and function in HIV, using the primary outcome measures of myocardial inflammation/fibrosis and left atrial volume index.

\section{Angiotensin-Converting Enzyme Inhibitors}

Since some evidence has suggested a potential role for angiotensin II in the pathophysiology of exercise intolerance in HFpEF patients [36-40], angiotensin antagonism has been hypothesized to be of interest in targeting exercise intolerance in older patients with HFpEF. The first study evaluating angiotensin-converting enzyme inhibitors, the PEP-CHF trial, evaluated perindopril's effects on elderly patients with EF between 40 and 50\% [41]. The trial failed to achieve its primary endpoint (composite of all-cause mortality or unplanned heart failure related hospitalization) for several reasons, including low event rate and large number of patients stopping assigned treatment after 1 year. The reduction in hospitalizations for $\mathrm{HF}$ and the reduction in primary endpoint approached conventional levels of statistical significance over the first year of follow-up. However, the trial did not show a statistical significant benefit of the drug on long-term morbidity and mortality. Enalapril was recently evaluated for its effect on exercise capacity and aortic distensibility in patients presenting with diastolic dysfunction (EF > 50\%) (NCT01411735). Unfortunately, this study showed that enalapril administration failed to meet the defined endpoints, with no improvement seen on exercise 
capacity, aortic distensibility, or LV mass and volume after 12-month treatment [42].

\section{Angiotensin Receptor Blockers}

Similarly to what was hypothesized with angiotensin-converting enzyme inhibitors, angiotensin receptor blockers have been thought to be of benefit in patients with HFpEF. The CHARM-preserved study (NCT00634712) evaluated the effects of candesartan on the composite outcome of cardiovascular mortality or admission to hospital for worsening HF [43]. Though the trial found a trend towards fewer cardiovascular outcomes, favouring candesartan, it was moderate and of borderline significance. Even so, the numbers of individuals admitted one or more times for HF were reduced, reinforcing that candesartan might be of some benefit in this population [43]. The I-preserved trial (NCT00095238) evaluated irbesartan's effect on [44] the composite outcome of death from any cause or hospitalization for a protocolspecified cardiovascular cause in patients with HFpEF [44]. The trial found that treatment with irbesartan did not reduce the risk of death or hospitalization for cardiovascular causes, nor did it improve any of the secondary clinical outcomes, such as patient quality of life. Further studies found similar results in which the use of angiotensin receptor blockers did not significantly improve patients outcomes [45-47]. A recent systematic review and meta-analysis of both randomized trials and observational studies found that both angiotensin-converting enzyme inhibitor and angiotensin receptor blockers were associated with a modest, but statistically significant, reduction in all-cause mortality in $\mathrm{HFpEF}$ patients [48]. However, in randomized trials alone, this effect was not seen. The results from this meta-analysis suggest that it may be important to further investigate these pharmacological classes in patients with HFpEF [48].

\section{Aldosterone Receptor Antagonists}

The first major clinical trial using spironolactone for $\mathrm{HFpEF}$ was the TOPCAT trial (NCT00094302). While it did fail to meet the primary composite outcome of cardiovascular mortality, aborted cardiac arrest, or HF-related hospitalizations, the spironolactone arm showed a significantly lower rate of hospitalizations for the management of a HF exacerbation (risk ratio $0.83,95 \% \mathrm{CI}(0.69-0.99), p=0.042$ ), despite not having an effect in the number of all-cause hospitalization [49]. Furthermore, patients taking spironolactone showed significantly greater incidences for hyperkalemia and increased serum creatinine levels [49]. However, some important differences in baseline characteristics were noted. The majority of the patients enrolled from Russia and Georgia had been hospitalized for HF in the 12 months prior to randomization, whereas patients enrolled from the USA,
Canada, Argentina, and Brazil were more evenly balanced between hospitalized and non-hospitalized strata. Indeed, there was a marked regional variation in event rates, with patients on placebo group who had been enrolled in Russia or Georgia having a much lower likelihood of a primary outcome event than those enrolled in the Americas [49]. The discrepancy in event rates in the placebo group could have contributed to the observed treatment benefit in the Americas that was not seen in Russia or Georgia. In a post hoc subgroup analysis, the potential benefit of spironolactone with respect to the primary outcome was greatest in patients at the lower end of the EF spectrum $(\mathrm{EF}<50 \%)$, most prominently found in patients enrolled in the Americas [50]. TreatmentEF interaction for the primary outcome was somewhat more pronounced in men $(p=0.01)$ than in females $(p>0.80)$ [50]. Given the FDA's latest endorsement of sacubitril-valsartan in HFpEF, this could be an important finding.

The suggestion that spironolactone was effective in HFpEF was the basis for two ongoing phase III trialsthe SPIRRIT-HF (NCT02901184) and the SPIRIT-HF trials (NCT04727073). Adding to these, we are waiting for the publication of the FINEARTS-HF clinical trial (NCT04435626) results, studying the effects of finerenone in HFpEF, a drug that showed robust results in the ARTSHF phase IIb trial, not only in regard to safety, but also in the clinical outcome of patients medicated with $10-20 \mathrm{mg}$ of finerenone (compared to eplerenone, using a composite endpoint of "death from any cause, cardiovascular hospitalizations, or emergency presentation for worsening HF" within 90 days) [51].

\section{SGLT2 Inhibitors}

Clinical trials investigating the therapeutic implications of SGLT2 inhibitors in HFpEF have focused primarily on the effects of dapagliflozin (NCT03619213, NCT03877224) and empagliflozin (NCT03057951, NCT03448406, IRCT20190122042450N2).

The EMPERIAL-preserved trial (NCT03448406) found that empagliflozin had no significant effects in patients' exercise ability (measured through the 6MWTD), although treated patients displayed improvements in quality of life (measured through the KCCQ score), compared with placebo arm [52].The EMPEROR-preserved trial studied the effects of empagliflozin in a composite primary endpoint of cardiovascular death or hospitalization for HF in patients with HFpEF. This trial found that empagliflozin significantly reduced the risk of the primary endpoint in patients with HFpEF (hazard ratio 0.79, 95\% CI (0.69-0.90)), regardless of the presence or absence of diabetes or patients' EF [53]. Furthermore, it also showed that empagliflozin reduced the relative risk of first and recurrent hospitalizations for $\mathrm{HF}$ and significantly slowed kidney function decline. Thus, the 
EMPEROR-preserved trial has established empagliflozin as the first and only therapy, to date, to significantly reduce the risk of the composite of cardiovascular death or hospitalization for HF in adults with HFpEF. Nevertheless, it is important to note that empagliflozin's effect seems to diminish at $\mathrm{LVEF} \geq 60 \%$ (hazard ratio $0.87,95 \% \mathrm{CI}(0.69-1.10)$ ), suggesting that it is ineffective for patients in the upper range of EF.

A recent clinical trial is currently evaluating the combination of dapagliflozin and low dose of pioglitazone on hospitalization rate and all-cause mortality in patients with HFpEF (NCT03794518). Although not yet confirmed for HFpEF, dapagliflozin has been shown to reduce the risk of HF hospitalizations and cardiovascular death in patients with HFrEF [54]. Furthermore, pioglitazone has been associated with lower risk of recurrent major adverse cardiovascular events, stroke, or myocardial infarction, even though it has been shown it does not reduce the risk for all-cause mortality and might even increase the risk of development of HF [55]; the combination of both these drugs could yield interesting results in HFpEF.

\section{Phosphodiesterase Inhibitors}

Phosphodiesterase 5A has been found to reverse cardiac remodeling in hearts subjected to sustained pressure load [56] and to improve contractile function, quality of life, and exercise capacity in small scale, randomized, doubleblinded, placebo-controlled trials in patients with HFrEF [57-60], hinting towards a potential beneficial effect in patients with HFpEF. Different phosphodiesterase 5A inhibitors have been investigated in HFpEF: sildenafil (NCT01726049, NCT00763867), udenafil (NCT01599117), and tadalafil (DRKS00014595). Sildenafil has consistently failed to show beneficial effects in HFpEF. The RELAX trial (NCT00763867) found that phosphodiesterase 5A inhibition had no effect on maximal or submaximal exercise capacity, clinical status, quality of live, LV remodeling, diastolic function parameters, or pulmonary artery systolic pressure while also showing that treatment resulted in further worsening of patients' renal function and led to increased levels of both NT-proBNP and uric acid [61]. A subsequent trial (NCT01726049) also reported no effects on hemodynamic parameters, such as mPAP, pulmonary capillary wedge pressure (PCWP), and cardiac output (CO), as well as no improvement in cardiac structure or function, cardiopulmonary exercise testing, laboratory parameters, or quality of life in patients with $\mathrm{HFpEF}$ and group $2 \mathrm{PH}[62,63]$. Results regarding the trials with udenafil and enapril have yet to be reported.

Recently, a type III phosphodiesterase inhibitor, milrinone, has been evaluated for its hemodynamic effects in patients with HFpEF $[64,65]$. Although milrinone showed no improvement on patients' rate of isovolumic relaxation, LV stiffness, and minimal effect in end-diastolic pressure-volume relationships, it decreased right atrium pressure, mPAP, and PCWP during exercise suggesting that it might represent a relevant therapeutic option for HFpEF; however, pharmacological modulation of other cardiovascular parameters might be required to achieve optimal effects [64].

\section{Prostaglandin Analogs}

Prostaglandin analogs have been approved for the treatment of pulmonary arterial hypertension due to their vasodilatory effect [66]. Since PH due to left heart disease, and mainly HFpEF, is the most frequent cause of $\mathrm{PH}$ worldwide, prostaglandin analogs such as treprostinil have been evaluated for their effectiveness in subjects with $\mathrm{PH}$ associated with HFpEF (NCT03037580, NCT03043651). These trials were terminated by the sponsor due to slow enrolment, and due to the reduced number of subjects, efficacy-related endpoints were not analyzed, so its value as a novel therapeutic option for HFpEF remains unknown.

\section{GLP-1 Analogs and GLP-Receptor Agonists}

Small pilot studies in diabetic patients with $\mathrm{HF}$ (EF $<35 \%$, NYHA III-IV) have found that GLP-1 analogs, such as exenatide, significantly increase patients cardiac index while decreasing PCWP shortly after infusion [67]. Continuous, 5-week infusion of recombinant GLP-1 was also associated with improved EF, Minnesota Quality of Life score, 6MWTD, and exercise peak $\mathrm{VO}_{2}$, effects similar in magnitude in both diabetic and non-diabetic patients [68]. A subsequent study found that GLP-receptor agonist, albiglutide, administration in subjects with $\mathrm{EF}<40 \%$, NYHA II-III, significantly improved peak $\mathrm{VO}_{2}$, but showed no effects in left ventricle (LV) size or function, 6MWTD, or quality of life scores [69]. Larger clinical trials such as the LIVE trial (NCT01472640) and the FIGHT trial (NCT01800968) have evaluated the effect of liraglutide, a GLP-receptor agonist, in patients with HFrEF. The LIVE trial found that liraglutide did not significantly affect patients' systolic function but did result in weight loss, improved glycemic control, and improved physical performance [70]. It is important to note that serious adverse cardiac events occurred more often with liraglutide than with placebo [71]. The results from the FIGHT trial were neutral overall, showing no differences in outcomes, functional capacity, or post-hospitalization stability. Overall, these findings suggest that GLP-1 analogs and GLP-receptor agonist could show promising results in patients with HFpEF. Currently, three studies are evaluating both semaglutide's and tirzepatide's effects in patients 
with HFpEF and obesity and/or type 2 diabetes mellitus (NCT04788511, NCT04916470, NCT04847557).

\section{Iron Products}

Iron deficiency is a widespread comorbidity among HF patients [72], associated with longer hospital stays and higher healthcare costs [73]. While it has been thoroughly studied in patients with HFrEF, with strong evidence suggesting its association with decreased exercise capacity and quality of life, and treatment has both been tested and approved with demonstrated clinical benefit [74-77], there is less evidence when it comes to its association with HFpEF [78] with some studies suggesting it might be associated with reduced functional capacity and decreased quality of life [79-81]. The PREFER-HF trial (NCT03833336) evaluated the effects of iron therapy in patients with HFpEF and iron deficiency, although, to date, no results have been reported.

\section{Anti-inflammatory Drugs}

Because activation of inflammatory pathways has long been suggested to contribute to the pathogenesis of HF [82-84], some clinical trials have evaluated the effects antiinflammatory drugs in patients with HF. A recent clinical trial has studied the efficacy of colchicine in patients with stable chronic HF (EF $\leq 40 \%$ ) [85]. In this study, while colchicine was proven to be effective in reducing inflammatory biomarker levels, it did not affect patients' functional status, regarding NYHA functional class or exercise tolerance. These results warrant attention to the newly initiated COLpEF (NCT04857931) trial, investigating colchicine in HFpEF, especially since the study's primary outcome measures are changes in C-reactive protein, with no particular focus on improvement of patients' cardiac functional status and symptoms.

\section{B2 Adrenergic Receptor Agonists}

Because pulmonary vascular resistance fails to decrease appropriately during exercise in patients with HFpEF, Reddy et al. hypothesized that drugs that enhanced pulmonary vasodilation, such as albuterol, could display a beneficial effect in these subjects (NCT02885636) [86]. In this trial, inhaled albuterol showed favorable effects on pulmonary vascular load during exercise, coupled with improvements in cardiac output reserve, right ventricular-pulmonary artery coupling, and left heart filling while maintaining pulmonary capillary hydrostatic pressures. Even though this study did not report LV functional responses to albuterol nor chronic effects, it suggests, overall, a possible role of $\beta 2$ adrenergic receptor agonists in the treatment of HFpEF.

\section{Hyperpolarization-Activated Cyclic Nucleotide-Gated Channel Blockers}

There is one active trial on the effects of ivabradine in HFpEF (jRCTs051200059), for which there are still no published results. Going back to 2017, the EDIFY clinical trial (EudraCT no. 2012 002,742 20) showed that ivabradineinduced heart rate reduction failed to improve the following outcomes in HFpEF patients: echo-Doppler E/e' ratio, 6MWTD, and plasma NT-proBNP concentration. Despite the disappointing results, this trial showed no concerns regarding the safety of the drug [87]. However, regarding the safety of ivabradine, in patients with coronary artery disease (but without HF), there was a $20 \%$ increase in HF-related hospital admissions [88]. As these diseases often come hand in hand, these results could be a cause for concern with the use of ivabradine in HFpEF.

\section{Guanylate Cyclase Stimulators}

Guanylate cyclase (GC) triggering by nitric oxide (NO) promotes vasodilation and inhibits smooth muscle cell proliferation, platelet aggregation, and vascular remodeling [89]. Since several cardiovascular diseases are associated with NO/GC-signaling pathway dysfunction [90, 91], GC stimulation could show potential benefits through the enhancement of the affinity of GC even at very low levels of NO [92].

Currently, 3 different GC stimulators are being studied in HFpEF: IW-1973 (NCT03254485), riociguat (NCT02744339), and vericiguat (NCT03547583 and NCT01951638). Of those, the VITALITY-HFpEF trial (NCT03547583) found that 24-week treatment with vericiguat at either 15 or $10 \mathrm{mg} /$ day did not improve either the KCCQ physical limitation score or the 6MWTD, when compared with placebo [93]. These results contrast with those previously reported in the SOCRATES-PRESERVED trial (NCT01951638), where vericiguat, even with a smaller dosage than the one used in the VITALITY-HFpEF trial, was shown to improve patients' KCCQ physical limitation score [94]. The differing results between these trials warrants attention and mandates further investigation.

\section{NO-Donating Drugs}

All past and ongoing trials using nitrates and nitrites are currently in phase II at most, having yet to show enough safety and effectiveness to warrant phase III trials to begin.

Despite the disappointing results of organic nitrates, inorganic formulations given in the form of nitrate-rich beetroot 
juice (12.9 mmol of $\mathrm{NO}_{3}{ }^{-}$in $140 \mathrm{~mL}$ ) have been investigated for its effects in exercise capacity in patients with HFpEF (NCT01919177) [95]. It was found that patients receiving inorganic nitrate showed no changes in exercise efficiency (total work/total oxygen consumed), the trial's primary endpoint. However, a single dose of inorganic nitrate prior to exercise significantly improved peak $\mathrm{VO}_{2}$ while also decreasing systemic vascular resistance and increasing $\mathrm{CO}$ at peak exercise. Overall, these results suggest some degree of improvement of exercise capacity in HFpEF patients with inorganic nitrate supplementation. Nevertheless, these should be confirmed in larger cohort studies that also evaluate inorganic nitrates' long-term effects and its impact in parameters other that exercise capacity.

Inorganic nitrite has been recognized as an alternative source of NO-cGMP that is independent of the traditional NO synthase pathway [96-99]. Inorganic nitrite is reduced to NO particularly under conditions of tissue hypoxia and acidosis [98], suggesting it could selectively target hemodynamic alterations induced by stress in $\operatorname{HFpEF}[100,101]$.

Several clinical trials have investigated the effects of inorganic nitrites in HFpEF. To our knowledge, the first study investigating inorganic nitrites in HFpEF (NCT01932606) found that intravenous sodium nitrite administration significantly improved exercise PCWP, resulting in a $37 \%$ reduction in left heart filling pressures with exercise [102]. Furthermore, nitrite therapy was associated with beneficial myocardial effects such as increased in LV stroke work with exercise, an integrated index of LV diastolic and systolic performance. Beneficial effects were of great magnitude during exercise compared with at rest. In another trial investigating nebulized inhaled sodium nitrite (NCT02262078), it was found that, similarly to the intravenous administration route, inorganic nitrate reduces PCWP both at rest and, particularly, during exercise [103]. However, a posterior trial (NCT02742129) found that inhaled sodium nitrate did not improve peak aerobic capacity, daily activity levels, or quality of life scores, contrasting with previous results and warranting attention to the drug as a HFpEF therapeutic option [104].

Several other clinical trials testing alternative formulations targeting the inorganic nitrate/nitrite pathway are currently under way-NCT02918552, NCT01919177, NCT03015402, NCT02980068, NCT02840799, NCT03289481, and NCT02713126.

\section{Late Sodium Current Inhibitors}

Since late sodium current is abnormally elevated in HF [105], and its inhibition improves diastolic performance in ischemic myocardium [106], there is ongoing effort to investigate the possible effects of ranolazine in HFpEF, with the
RALI-DHF (NCT01163734) being the main trial for this research.

The RALI-DHF trial found that ranolazine improved hemodynamic measurements but had no effects in relaxation parameters [107]. It was found that ranazoline infused intravenously over $24 \mathrm{~h}$ resulted in immediate, albeit modest, improvements in left ventricle (LV) end-diastolic pressure, $\mathrm{PCWP}$, and mPAP, suggesting a potential role in the treatment of diastolic dysfunction. Despite this, $\mathrm{CO}$ and stroke volume were decreased in the presence of ranazoline, pointing towards an acute reduction of systolic function, which could offset the positive effects of the drug on diastolic function. After 14 days of treatment, no significant changes were found in echocardiographic parameters or exercise tests, showing no evidence that acute changes induced by ranazoline would be predictive of long-term benefits.

\section{Calcium Sensitizers}

Cardiac troponin $\mathrm{C}$ acts as a $\mathrm{Ca}^{2+}$-operated molecular switch that turns myocardial force production on and off during systoles and diastoles [108]. Therefore, the kinetics and extent of contraction and relaxation of the heart are both coordinated by the $\mathrm{Ca}^{2+}$-binding characteristics of cardiac troponin C. Levosimendan is a $\mathrm{Ca}^{2+}$ sensitizer that, in patients with $\mathrm{HFrEF}$, has been shown to produce dose-dependent increases of $\mathrm{CO}$ and decreases of PCWP, central venous pressure, peripheral vascular resistance, and systemic vascular resistance (NCT01536132, NCT00988806, NCT01065194) [109]. Because these effects would also be beneficial for patients with HFpEF, it has been recently evaluated in phase II trials (NCT03624010, NCT03541603).

The HELP trial (NCT03541603) has found that $24 \mathrm{~h}$ infusion of levosimendan in patients with $\mathrm{PH}$ in the setting of HFpEF resulted in significantly decreased PCWP and central venous pressure at rest, although these parameters were not altered during exercise [110]. Furthermore, submaximal exercise capacity, measured by 6MWTD, was also improved. These are encouraging findings that justify further study of the applicability of levosimendan in patients with $\mathrm{PH}$ in the setting of HFpEF.

\section{Future Perspectives}

Due to the complexity of the data and heterogeneity of patients, the identification of distinct clinical phenotypes using machine learning may allow for more targeted diagnostics and personalized therapeutic options [119]. Cohen et al. identified three distinct phenogroups that displayed differences in circulating biomarkers, cardiac/arterial characteristics, and prognosis among TOPCAT trial participants [120]. Interestingly, spironolactone therapy was associated 
with a more pronounced reduction in the risk of cardiovascular death, HF hospitalization, or aborted cardiac arrest in patients with more functional impairment, higher comorbidity burden, and the worse overall prognosis but did not appear to substantially benefit other phenogroups. In the absence of clear effective therapeutic options to improve prognosis and given the heterogeneity of risk factors and outcomes in HFpEF, the separation and identification of individuals into subgroups could aid the identification of patients who would mostly likely benefit from targeted interventions.

These nuances regarding the different subgroups of HF and the presence of different comorbidities could be the cause for some of the disappointing results in past clinical trials and need to be considered when designing future trials and tailoring future therapies.

The number of enrolled patients in some trials is often lackluster, creating the possibility that some beneficial therapies might go unnoticed because only of lack of statistical power. Not only this, but the endpoints of some of the trials need to be better defined, focusing more on clinical outcomes than on biochemical markers that in the end do not correlate as well as expected to the desired clinical outcomes. Furthermore, a confusing factor in the interpretation of these clinical trials is the heterogeneity in the LVEF thresholds adopted [121]. Current inclusion criteria range from $\geq 40 \%$ and $>40 \%$ to $\geq 45 \%$, including patients with mildly reduced ejection fraction, considered by the European Society of Cardiology as heart failure with mid-range ejection fraction. The definition of LVEF threshold seems to be a relevant point because the largest benefits on the primary endpoints were recorded for LVEF ranging between 40 and $50 \%$, while the same treatments were found to be ineffective for patients in the upper range of $\mathrm{EF}(>60 \%)$ [121].

There is a need not only for new clinical trials results using different pharmacological classes, but also for more retrospective studies on the drugs currently empirically used for HFpEF without strong evidence, such as betablockers, on one hand to ensure patients are taking only the necessary drugs (as all have potential side effects) and on the other end of the spectrum to ensure clinicians that these drugs do not have deleterious cardiovascular effects when used for HFpEF.

Author Contribution All authors scientifically structured, wrote, and revised the manuscript. The manuscript, or part of it, has neither been published nor is currently under consideration for publication by any other journal. All authors have read the manuscript, agreed with its content, and approved its submission to Cardiovascular Drugs and Therapy Journal.

Funding This work was supported by the Portuguese Foundation for Science and Technology, under the scope of the Cardiovascular
R\&D Center - UnIC [UIDB/00051/2020 and UIDP/00051/2020] and projects IMPAcT [PTDC/MED-FSL/31719/2017; POCI-01-0145FEDER-031719], NETDIAMOND [POCI-01-0145-FEDER-016385], and DOCnet [NORTE-01-0145-FEDER-000003, NORTE_2020, under PORTUGAL_2020 Partnership].

Availability of Data and Material Not applicable.

Code Availability Not applicable.

\section{Declarations}

Conflict of Interest The authors declare no competing interests.

\section{References}

1. Pfeffer MA, Shah AM, Borlaug BA. Heart failure with preserved ejection fraction in perspective. Circ Res. 2019;124(11):1598-617.

2. Lam CS, Donal E, Kraigher-Krainer E, Vasan RS. Epidemiology and clinical course of heart failure with preserved ejection fraction. Eur J Heart Fail. 2011;13(1):18-28.

3. Hwang SJ, Melenovsky V, Borlaug BA. Implications of coronary artery disease in heart failure with preserved ejection fraction. J Am Coll Cardiol. 2014;63(25 Pt A):2817-27.

4. Tadic M, Cuspidi C. Obesity and heart failure with preserved ejection fraction: a paradox or something else? Heart Fail Rev. 2019;24(3):379-85

5. Bouthoorn S, Valstar GB, Gohar A, den Ruijter HM, Reitsma HB, Hoes AW, et al. The prevalence of left ventricular diastolic dysfunction and heart failure with preserved ejection fraction in men and women with type 2 diabetes: A systematic review and meta-analysis. Diab Vasc Dis Res. 2018;15(6):477-93.

6. Mentz RJ, Kelly JP, von Lueder TG, Voors AA, Lam CS, Cowie MR, et al. Noncardiac comorbidities in heart failure with reduced versus preserved ejection fraction. J Am Coll Cardiol. 2014;64(21):2281-93.

7. McAlister FA, Ezekowitz J, Tarantini L, Squire I, Komajda M, Bayes-Genis A, et al. Renal dysfunction in patients with heart failure with preserved versus reduced ejection fraction: impact of the new Chronic Kidney Disease-Epidemiology Collaboration Group formula. Circulation: Heart Failure. 2012;5(3):309-14.

8. Freaney PM, Shah SJ, Khan SS. COVID-19 and heart failure with preserved ejection fraction. JAMA. 2020;324(15):1499-500.

9. Cook C, Cole G, Asaria P, Jabbour R, Francis DP. The annual global economic burden of heart failure. Int J Cardiol. 2014;171(3):368-76.

10. Shafie AA, Tan YP, Ng CH. Systematic review of economic burden of heart failure. Heart Fail Rev. 2018;23(1):131-45.

11. Clark H, Rana R, Gow J, Pearson M, van der Touw T, Smart N. Hospitalisation costs associated with heart failure with preserved ejection fraction (HFpEF): a systematic review. Heart Fail Rev. 2021.

12. Paulus WJ, van Ballegoij JJ. Treatment of heart failure with normal ejection fraction: an inconvenient truth! J Am Coll Cardiol. 2010;55(6):526-37.

13. Ponikowski P, Voors AA, Anker SD, Bueno H, Cleland JG, Coats AJ, et al. 2016 ESC Guidelines for the diagnosis and treatment of acute and chronic heart failure: the task force for the diagnosis and treatment of acute and chronic heart failure of the European 
Society of Cardiology (ESC). Developed with the special contribution of the Heart Failure Association (HFA) of the ESC. Eur J Heart Fail. 2016;18(8):891-975.

14. Gevaert AB, Boen JRA, Segers VF, Van Craenenbroeck EM. Heart Failure With Preserved Ejection Fraction: A Review of Cardiac and Noncardiac Pathophysiology. Front Physiol. 2019;10:638.

15. Borlaug BA, Kass DA. Mechanisms of diastolic dysfunction in heart failure. Trends Cardiovasc Med. 2006;16(8):273-9.

16. Borlaug BA, Paulus WJ. Heart failure with preserved ejection fraction: pathophysiology, diagnosis, and treatment. Eur Heart J. 2011;32(6):670-9.

17. Netticadan T, Temsah RM, Kawabata K, Dhalla NS. Sarcoplas-

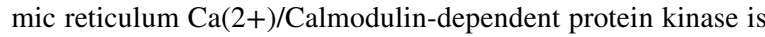
altered in heart failure. Circ Res. 2000;86(5):596-605.

18. Frank KF, Bolck B, Brixius K, Kranias EG, Schwinger RH. Modulation of SERCA: implications for the failing human heart. Basic Res Cardiol. 2002;97(Suppl 1):I72-8.

19. Neagoe C, Opitz CA, Makarenko I, Linke WA. Gigantic variety: expression patterns of titin isoforms in striated muscles and consequences for myofibrillar passive stiffness. J Muscle Res Cell Motil. 2003;24(2-3):175-89.

20. Kruger M, Kotter S, Grutzner A, Lang P, Andresen C, Redfield $\mathrm{MM}$, et al. Protein kinase G modulates human myocardial passive stiffness by phosphorylation of the titin springs. Circ Res. 2009;104(1):87-94.

21. Grutzner A, Garcia-Manyes S, Kotter S, Badilla CL, Fernandez JM, Linke WA. Modulation of titin-based stiffness by disulfide bonding in the cardiac titin N2-B unique sequence. Biophys J. 2009;97(3):825-34.

22. Paulus WJ, Tschope C. A novel paradigm for heart failure with preserved ejection fraction: comorbidities drive myocardial dysfunction and remodeling through coronary microvascular endothelial inflammation. J Am Coll Cardiol. 2013;62(4):263-71.

23. McMurray JJ, Packer M, Desai AS, Gong J, Lefkowitz MP, Rizkala AR, et al. Angiotensin-neprilysin inhibition versus enalapril in heart failure. N Engl J Med. 2014;371(11):993-1004.

24. Senni M, Paulus WJ, Gavazzi A, Fraser AG, Díez J, Solomon $\mathrm{SD}$, et al. New strategies for heart failure with preserved ejection fraction: the importance of targeted therapies for heart failure phenotypes. Eur Heart J. 2014;35(40):2797-815.

25. Solomon SD, McMurray JJV, Anand IS, Ge J, Lam CSP, Maggioni AP, et al. Angiotensin-neprilysin inhibition in heart failure with preserved ejection fraction. $\mathrm{N}$ Engl $\mathrm{J}$ Med. 2019;381(17):1609-20.

26. Vaduganathan M, Claggett BL, Desai AS, Anker SD, Perrone SV, Janssens S, et al. Prior heart failure hospitalization, clinical outcomes, and response to sacubitril/valsartan compared with valsartan in HFpEF. J Am Coll Cardiol. 2020;75(3):245-54.

27. Solomon SD, Vaduganathan M, B LC, Packer M, Zile M, Swedberg K, et al. Sacubitril/valsartan across the spectrum of ejection fraction in heart failure. Circulation. 2020;141(5):352-61.

28. Flather MD, Shibata MC, Coats AJ, Van Veldhuisen DJ, Parkhomenko A, Borbola J, et al. Randomized trial to determine the effect of nebivolol on mortality and cardiovascular hospital admission in elderly patients with heart failure (SENIORS). Eur Heart J. 2005;26(3):215-25.

29. Yamamoto K, Origasa H, Hori M, Investigators JD. Effects of carvedilol on heart failure with preserved ejection fraction: the Japanese Diastolic Heart Failure Study (J-DHF). Eur J Heart Fail. 2013;15(1):110-8.

30. Cleland JGF, Bunting KV, Flather MD, Altman DG, Holmes J, Coats AJS, et al. Beta-blockers for heart failure with reduced, mid-range, and preserved ejection fraction: an individual patient-level analysis of double-blind randomized trials. Eur Heart J. 2018;39(1):26-35.

31. Suzuki S, Yoshihisa A, Sato Y, Kanno Y, Watanabe S, Abe S, et al. Clinical significance of get with the guidelines-heart failure risk score in patients with chronic heart failure after hospitalization. J Am Heart Assoc. 2018;7(17):e008316.

32. Cheng RK, Cox M, Neely ML, Heidenreich PA, Bhatt DL, Eapen $\mathrm{ZJ}$, et al. Outcomes in patients with heart failure with preserved, borderline, and reduced ejection fraction in the Medicare population. Am Heart J. 2014;168(5):721-30.

33. Bozkurt B, Ezekowitz J. Substance and substrate: LVEF and sex subgroup analyses of PARAGON-HF and PARADIGM-HF trials. Circulation. 2020;141(5):362-6.

34. Office EP. PARALLAX meets one primary endpoint in heart failure with preserved ejection fraction. 2020.

35. Solomon SD, Zile M, Pieske B, Voors A, Shah A, KraigherKrainer E, et al. The angiotensin receptor neprilysin inhibitor LCZ696 in heart failure with preserved ejection fraction: a phase 2 double-blind randomised controlled trial. The Lancet. 2012;380(9851):1387-95.

36. Barenbrock M, Spieker C, Hoeks AP, Zidek W, Rahn KH. Effect of lisinopril and metoprolol on arterial distensibility. Hypertension. 1994;23(1 Suppl):I161-3.

37. Clarkson PB, Wheeldon NM, MacFadyen RJ, Pringle SD, MacDonald TM. Effects of brain natriuretic peptide on exercise hemodynamics and neurohormones in isolated diastolic heart failure. Circulation. 1996;93(11):2037-42.

38. Michel JB, Heudes D, Michel O, Poitevin P, Philippe M, Scalbert E, et al. Effect of chronic ANG I-converting enzyme inhibition on aging processes. II Large arteries Am J Physiol. 1994;267(1 Pt 2):R124-35.

39. Eaton GM, Cody RJ, Binkley PF. Increased aortic impedance precedes peripheral vasoconstriction at the early stage of ventricular failure in the paced canine model. Circulation. 1993;88(6):2714-21.

40. Levy BI, Michel JB, Salzmann JL, Poitevin P, Devissaguet M, Scalbert E, et al. Long-term effects of angiotensin-converting enzyme inhibition on the arterial wall of adult spontaneously hypertensive rats. Am J Cardiol. 1993;71(17):E8-16.

41. Cleland JG, Tendera M, Adamus J, Freemantle N, Polonski $\mathrm{L}$, Taylor $\mathrm{J}$, et al. The perindopril in elderly people with chronic heart failure (PEP-CHF) study. Eur Heart J. 2006;27(19):2338-45.

42. Kitzman DW, Hundley WG, Brubaker PH, Morgan TM, Moore JB, Stewart KP, et al. A randomized double-blind trial of enalapril in older patients with heart failure and preserved ejection fraction: effects on exercise tolerance and arterial distensibility. Circ Heart Fail. 2010;3(4):477-85.

43. Yusuf S, Pfeffer MA, Swedberg K, Granger CB, Held P, McMurray JJV, et al. Effects of candesartan in patients with chronic heart failure and preserved left-ventricular ejection fraction: the CHARM-Preserved Trial. The Lancet. 2003;362(9386):777-81.

44. Massie BM, Carson PE, McMurray JJ, Komajda M, McKelvie R, Zile MR, et al. Irbesartan in patients with heart failure and preserved ejection fraction. N Engl J Med. 2008;359(23):2456-67.

45. Yip GW, Wang M, Wang T, Chan S, Fung JW, Yeung L, et al. The Hong Kong diastolic heart failure study: a randomised controlled trial of diuretics, irbesartan and ramipril on quality of life, exercise capacity, left ventricular global and regional function in heart failure with a normal ejection fraction. Heart. 2008;94(5):573-80.

46. Parthasarathy HK, Pieske B, Weisskopf M, Andrews CD, Brunel $\mathrm{P}$, Struthers AD, et al. A randomized, double-blind, placebocontrolled study to determine the effects of valsartan on exercise 
time in patients with symptomatic heart failure with preserved ejection fraction. Eur J Heart Fail. 2009;11(10):980-9.

47. Patel K, Fonarow GC, Kitzman DW, Aban IB, Love TE, Allman RM, et al. Angiotensin receptor blockers and outcomes in realworld older patients with heart failure and preserved ejection fraction: a propensity-matched inception cohort clinical effectiveness study. Eur J Heart Fail. 2012;14(10):1179-88.

48. Khan MS, Fonarow GC, Khan H, Greene SJ, Anker SD, Gheorghiade $\mathrm{M}$, et al. Renin-angiotensin blockade in heart failure with preserved ejection fraction: a systematic review and metaanalysis. ESC Heart Fail. 2017;4(4):402-8.

49. Pitt B, Pfeffer MA, Assmann SF, Boineau R, Anand IS, Claggett $\mathrm{B}$, et al. Spironolactone for heart failure with preserved ejection fraction. N Engl J Med. 2014;370(15):1383-92.

50. Solomon SD, Claggett B, Lewis EF, Desai A, Anand I, Sweitzer $\mathrm{NK}$, et al. Influence of ejection fraction on outcomes and efficacy of spironolactone in patients with heart failure with preserved ejection fraction. Eur Heart J. 2016;37(5):455-62.

51. Filippatos G, Anker SD, Böhm M, Gheorghiade M, Køber L, Krum H, et al. A randomized controlled study of finerenone vs. eplerenone in patients with worsening chronic heart failure and diabetes mellitus and/or chronic kidney disease. Eur Heart J. 2016;37(27):2105-14.

52. Company ELa: Full results from EMPERIAL exercise ability trials presented. https://www.prnewswire.com/news-releases/ full-results-from-emperial-exercise-ability-trials-presented301080354.html (2021). Accessed.

53. Anker SD, Butler J, Filippatos G, Ferreira JP, Bocchi E, Bohm $\mathrm{M}$, et al. Empagliflozin in heart failure with a preserved ejection fraction. N Engl J Med. 2021;385(16):1451-61.

54. Jhund PS, Ponikowski P, Docherty KF, Gasparyan SB, Bohm $\mathrm{M}$, Chiang CE, et al. Dapagliflozin and recurrent heart failure hospitalizations in heart failure with reduced ejection fraction: an analysis of DAPA-HF. Circulation. 2021;143(20):1962-72.

55. de Jong M, van der Worp HB, van der Graaf Y, Visseren FLJ, Westerink J. Pioglitazone and the secondary prevention of cardiovascular disease. A meta-analysis of randomized-controlled trials. Cardiovasc Diabetol. 2017;16(1):134.

56. Takimoto E, Champion HC, Li M, Belardi D, Ren S, Rodriguez ER, et al. Chronic inhibition of cyclic GMP phosphodiesterase $5 \mathrm{~A}$ prevents and reverses cardiac hypertrophy. Nat Med. 2005; 11(2):214-22.

57. Guazzi M, Vicenzi M, Arena R, Guazzi MD. PDE5 inhibition with sildenafil improves left ventricular diastolic function, cardiac geometry, and clinical status in patients with stable systolic heart failure: results of a 1-year, prospective, randomized, placebo-controlled study. Circ Heart Fail. 2011;4(1):8-17.

58. Kim KH, Kim HK, Hwang IC, Cho HJ, Je N, Kwon OM, et al. PDE 5 inhibition with udenafil improves left ventricular systolic/diastolic functions and exercise capacity in patients with chronic heart failure with reduced ejection fraction; a 12-week, randomized, double-blind, placebo-controlled trial. Am Heart J. 2015;169(6):813-22.e3.

59. Lewis GD, Shah R, Shahzad K, Camuso JM, Pappagianopoulos PP, Hung J, et al. Sildenafil improves exercise capacity and quality of life in patients with systolic heart failure and secondary pulmonary hypertension. Circulation. 2007;116(14):1555-62.

60. Zhuang XD, Long M, Li F, Hu X, Liao XX, Du ZM. PDE5 inhibitor sildenafil in the treatment of heart failure: a meta-analysis of randomized controlled trials. Int J Cardiol. 2014;172(3):581-7.

61. Redfield MM, Chen HH, Borlaug BA, Semigran MJ, Lee KL, Lewis G, et al. Effect of phosphodiesterase-5 inhibition on exercise capacity and clinical status in heart failure with preserved ejection fraction: a randomized clinical trial. JAMA. 2013;309(12):1268-77.
62. Hoendermis ES, Liu LC, Hummel YM, van der Meer P, de Boer RA, Berger RM, et al. Effects of sildenafil on invasive haemodynamics and exercise capacity in heart failure patients with preserved ejection fraction and pulmonary hypertension: a randomized controlled trial. Eur Heart J. 2015;36(38):2565-73.

63. Liu LC, Hummel YM, van der Meer P, Berger RM, Damman K, van Veldhuisen DJ, et al. Effects of sildenafil on cardiac structure and function, cardiopulmonary exercise testing and health-related quality of life measures in heart failure patients with preserved ejection fraction and pulmonary hypertension. Eur J Heart Fail. 2017;19(1):116-25.

64. Kaye DM, Byrne M, Mariani J, Nanayakkara S, Burkhoff D. Identification of physiologic treatment targets with favourable haemodynamic consequences in heart failure with preserved ejection fraction. ESC Heart Fail. 2020.

65. Kaye DM, Nanayakkara S, Vizi D, Byrne M, Mariani JA. Effects of milrinone on rest and exercise hemodynamics in heart failure with preserved ejection fraction. J Am Coll Cardiol. 2016;67(21):2554-6.

66. Simonneau G, Barst RJ, Galie N, Naeije R, Rich S, Bourge RC, et al. Continuous subcutaneous infusion of treprostinil, a prostacyclin analogue, in patients with pulmonary arterial hypertension: a double-blind, randomized, placebo-controlled trial. Am J Respir Crit Care Med. 2002;165(6):800-4.

67. Nathanson D, Ullman B, Lofstrom U, Hedman A, Frick M, Sjoholm A, et al. Effects of intravenous exenatide in type 2 diabetic patients with congestive heart failure: a double-blind, randomised controlled clinical trial of efficacy and safety. Diabetologia. 2012;55(4):926-35.

68. Sokos GG, Nikolaidis LA, Mankad S, Elahi D, Shannon RP. Glucagon-like peptide-1 infusion improves left ventricular ejection fraction and functional status in patients with chronic heart failure. J Card Fail. 2006;12(9):694-9.

69. Lepore JJ, Olson E, Demopoulos L, Haws T, Fang Z, Barbour AM, et al. Effects of the novel long-acting GLP-1 agonist, albiglutide, on cardiac function, cardiac metabolism, and exercise capacity in patients with chronic heart failure and reduced ejection fraction. JACC Heart Fail. 2016;4(7):559-66.

70. Jorsal A, Kistorp C, Holmager P, Tougaard RS, Nielsen R, Hanselmann A, et al. Effect of liraglutide, a glucagon-like peptide- 1 analogue, on left ventricular function in stable chronic heart failure patients with and without diabetes (LIVE)-a multicentre, double-blind, randomised, placebo-controlled trial. Eur J Heart Fail. 2017;19(1):69-77.

71. Khan MS, Fonarow GC, McGuire DK, Hernandez AF, Vaduganathan $\mathrm{M}$, Rosenstock J, et al. Glucagon-like peptide 1 receptor agonists and heart failure: the need for further evidence generation and practice guidelines optimization. Circulation. 2020;142(12):1205-18.

72. Martens P, Nijst P, Verbrugge FH, Smeets K, Dupont M, Mullens W. Impact of iron deficiency on exercise capacity and outcome in heart failure with reduced, mid-range and preserved ejection fraction. Acta Cardiol. 2018;73(2):115-23.

73. Beattie JM, Khatib R, Phillips CJ, Williams SG. Iron deficiency in 78805 people admitted with heart failure across England: a retrospective cohort study. Open Heart. 2020;7(1): e001153.

74. Nunez J, Monmeneu JV, Mollar A, Nunez E, Bodi V, Minana G, et al. Left ventricular ejection fraction recovery in patients with heart failure treated with intravenous iron: a pilot study. ESC Heart Fail. 2016;3(4):293-8.

75. Moliner P, Jankowska EA, van Veldhuisen DJ, Farre N, Rozentryt $\mathrm{P}$, Enjuanes C, et al. Clinical correlates and prognostic impact of impaired iron storage versus impaired iron transport in an international cohort of 1821 patients with chronic heart failure. Int J Cardiol. 2017;243:360-6. 
76. Enjuanes C, Bruguera J, Grau M, Cladellas M, Gonzalez G, Merono $\mathrm{O}$, et al. Iron status in chronic heart failure: impact on symptoms, functional class and submaximal exercise capacity. Rev Esp Cardiol (Engl Ed). 2016;69(3):247-55.

77. Comin-Colet J, Enjuanes C, Gonzalez G, Torrens A, Cladellas M, Merono $\mathrm{O}$, et al. Iron deficiency is a key determinant of healthrelated quality of life in patients with chronic heart failure regardless of anaemia status. Eur J Heart Fail. 2013;15(10):1164-72.

78. Beale AL, Warren JL, Roberts N, Meyer P, Townsend NP, Kaye D. Iron deficiency in heart failure with preserved ejection fraction: a systematic review and meta-analysis. Open Heart. 2019;6(1): e001012.

79. Nunez J, Dominguez E, Ramon JM, Nunez E, Sanchis J, Santas $\mathrm{E}$, et al. Iron deficiency and functional capacity in patients with advanced heart failure with preserved ejection fraction. Int J Cardiol. 2016;207:365-7.

80. Bekfani T, Pellicori P, Morris D, Ebner N, Valentova M, Sandek A, et al. Iron deficiency in patients with heart failure with preserved ejection fraction and its association with reduced exercise capacity, muscle strength and quality of life. Clin Res Cardiol. 2019;108(2):203-11.

81. Alcaide-Aldeano A, Garay A, Alcoberro L, Jimenez-Marrero S, Yun S, Tajes M, et al. Iron deficiency: impact on functional capacity and quality of life in heart failure with preserved ejection fraction. J Clin Med. 2020;9(4).

82. Deswal A, Petersen NJ, Feldman AM, Young JB, White BG, Mann DL. Cytokines and cytokine receptors in advanced heart failure: an analysis of the cytokine database from the Vesnarinone trial (VEST). Circulation. 2001;103(16):2055-9.

83. Mann DL, Young JB. Basic mechanisms in congestive heart failure. Recognizing the role of proinflammatory cytokines. Chest. 1994;105(3):897-904.

84. Rauchhaus M, Doehner W, Francis DP, Davos C, Kemp M, Liebenthal $\mathrm{C}$, et al. Plasma cytokine parameters and mortality in patients with chronic heart failure. Circulation. 2000;102(25):3060-7.

85. Deftereos S, Giannopoulos G, Panagopoulou V, Bouras G, Raisakis K, Kossyvakis C, et al. Anti-inflammatory treatment with colchicine in stable chronic heart failure: a prospective, randomized study. JACC Heart Fail. 2014;2(2):131-7.

86. Reddy YNV, Obokata M, Koepp KE, Egbe AC, Wiley B, Borlaug BA. The beta-adrenergic agonist albuterol improves pulmonary vascular reserve in heart failure with preserved ejection fraction. Circ Res. 2019;124(2):306-14.

87. Komajda M, Isnard R, Cohen-Solal A, Metra M, Pieske B, Ponikowski $\mathrm{P}$, et al. Effect of ivabradine in patients with heart failure with preserved ejection fraction: the EDIFY randomized placebo-controlled trial. Eur J Heart Fail. 2017;19(11):1495-503.

88. Fox K, Ford I, Steg PG, Tardif JC, Tendera M, Ferrari R, et al. Ivabradine in stable coronary artery disease without clinical heart failure. N Engl J Med. 2014;371(12):1091-9.

89. Sandner P, Zimmer DP, Milne GT, Follmann M, Hobbs A, Stasch JP. Soluble guanylate cyclase stimulators and activators. Handb Exp Pharmacol. 2021;264:355-94.

90. Klinger JR, Kadowitz PJ. The nitric oxide pathway in pulmonary vascular disease. Am J Cardiol. 2017;120(8s):S71-9.

91. Stasch JP, Pacher P, Evgenov OV. Soluble guanylate cyclase as an emerging therapeutic target in cardiopulmonary disease. Circulation. 2011;123(20):2263-73.

92. Zheng X, Zheng W, Xiong B, Huang J. The efficacy and safety of soluble guanylate cyclase stimulators in patients with heart failure: a systematic review and meta-analysis. Medicine (Baltimore). 2018;97(41): e12709.

93. Armstrong PW, Lam CSP, Anstrom KJ, Ezekowitz J, Hernandez AF, O'Connor CM, et al. Effect of vericiguat vs placebo on quality of life in patients with heart failure and preserved ejection fraction: the VITALITY-HFpEF randomized clinical trial. JAMA. 2020;324(15):1512-21.

94. Pieske B, Maggioni AP, Lam CSP, Pieske-Kraigher E, Filippatos $\mathrm{G}$, Butler J, et al. Vericiguat in patients with worsening chronic heart failure and preserved ejection fraction: results of the SOluble guanylate Cyclase stimulatoR in heArT failurE patientS with PRESERVED EF (SOCRATES-PRESERVED) study. Eur Heart J. 2017;38(15):1119-27.

95. Zamani P, Rawat D, Shiva-Kumar P, Geraci S, Bhuva R, Konda $\mathrm{P}$, et al. Effect of inorganic nitrate on exercise capacity in heart failure with preserved ejection fraction. Circulation. 2015;131(4):371-80; discussion 80.

96. Cosby K, Partovi KS, Crawford JH, Patel RP, Reiter CD, Martyr S, et al. Nitrite reduction to nitric oxide by deoxyhemoglobin vasodilates the human circulation. Nat Med. 2003;9(12):1498-505.

97. Dejam A, Hunter CJ, Tremonti C, Pluta RM, Hon YY, Grimes $\mathrm{G}$, et al. Nitrite infusion in humans and nonhuman primates: endocrine effects, pharmacokinetics, and tolerance formation. Circulation. 2007;116(16):1821-31.

98. Lundberg JO, Weitzberg E, Gladwin MT. The nitrate-nitritenitric oxide pathway in physiology and therapeutics. Nat Rev Drug Discov. 2008;7(2):156-67.

99. Maher AR, Milsom AB, Gunaruwan P, Abozguia K, Ahmed I, Weaver RA, et al. Hypoxic modulation of exogenous nitriteinduced vasodilation in humans. Circulation. 2008;117(5):670-7.

100. Abudiab MM, Redfield MM, Melenovsky V, Olson TP, Kass DA, Johnson BD, et al. Cardiac output response to exercise in relation to metabolic demand in heart failure with preserved ejection fraction. Eur J Heart Fail. 2013;15(7):776-85.

101. Borlaug BA, Nishimura RA, Sorajja P, Lam CS, Redfield MM. Exercise hemodynamics enhance diagnosis of early heart failure with preserved ejection fraction. Circ Heart Fail. 2010;3(5):588-95.

102. Borlaug BA, Koepp KE, Melenovsky V. Sodium Nitrite improves exercise hemodynamics and ventricular performance in heart failure with preserved ejection fraction. J Am Coll Cardiol. 2015;66(15):1672-82.

103. Borlaug BA, Melenovsky V, Koepp KE. Inhaled sodium nitrite improves rest and exercise hemodynamics in heart failure with preserved ejection fraction. Circ Res. 2016;119(7):880-6.

104. Borlaug BA, Anstrom KJ, Lewis GD, Shah SJ, Levine JA, Koepp GA, et al. Effect of inorganic nitrite vs placebo on exercise capacity among patients with heart failure with preserved ejection fraction: the INDIE-HFpEF randomized clinical trial. JAMA. 2018;320(17):1764-73.

105. Maltsev VA, Silverman N, Sabbah HN, Undrovinas AI. Chronic heart failure slows late sodium current in human and canine ventricular myocytes: implications for repolarization variability. Eur J Heart Fail. 2007;9(3):219-27.

106. Sossalla S, Maier LS. Role of ranolazine in angina, heart failure, arrhythmias, and diabetes. Pharmacol Ther. 2012;133(3):311-23.

107. Maier LS, Layug B, Karwatowska-Prokopczuk E, Belardinelli L, Lee S, Sander J, et al. RAnoLazIne for the treatment of diastolic heart failure in patients with preserved ejection fraction: the RALI-DHF proof-of-concept study. JACC Heart Fail. 2013;1(2):115-22.

108. Papp Z, Edes I, Fruhwald S, De Hert SG, Salmenpera M, Leppikangas $\mathrm{H}$, et al. Levosimendan: molecular mechanisms and clinical implications: consensus of experts on the mechanisms of action of levosimendan. Int J Cardiol. 2012;159(2):82-7.

109. Altenberger J, Gustafsson F, Harjola VP, Karason K, KindgenMilles D, Kivikko M, et al. Levosimendan in acute and advanced heart failure: an appraisal of the clinical database and evaluation of its therapeutic applications. J Cardiovasc Pharmacol. 2018;71(3):129-36. 
110. Burkhoff D, Borlaug BA, Shah SJ, Zolty R, Tedford RJ, Thenappan $\mathrm{T}$, et al. Levosimendan improves hemodynamics and exercise tolerance in PH-HFpEF: results of the randomized placebo-controlled HELP trial. JACC Heart Fail. 2021;9(5):360-70.

111. Udelson JE, Lewis GD, Shah SJ, Zile MR, Redfield MM, Burnett $\mathrm{J} \mathrm{Jr}$, et al. Effect of praliciguat on peak rate of oxygen consumption in patients with heart failure with preserved ejection fraction: the CAPACITY HFpEF randomized clinical trial. JAMA. 2020;324(15):1522-31.

112. Redfield MM, Anstrom KJ, Levine JA, Koepp GA, Borlaug BA, $\mathrm{Chen} \mathrm{HH}$, et al. Isosorbide mononitrate in heart failure with preserved ejection fraction. N Engl J Med. 2015;373(24):2314-24.

113. Snipelisky D, Kelly J, Levine JA, Koepp GA, Anstrom KJ, McNulty SE, et al. Accelerometer-measured daily activity in heart failure with preserved ejection fraction: clinical correlates and association with standard heart failure severity indices. Circ Heart Fail. 2017;10(6):e003878.

114. Zamani P, Akers S, Soto-Calderon H, Beraun M, Koppula MR, Varakantam S, et al. Isosorbide dinitrate, with or without hydralazine, does not reduce wave reflections, left ventricular hypertrophy, or myocardial fibrosis in patients with heart failure with preserved ejection fraction. J Am Heart Assoc. 2017;6(2).

115. Shah P, Pellicori P, Rimmer S, Rigby AS, Clark AL. Effect of increased inspired oxygen on exercise performance in patients with heart failure and normal ejection fraction. Int J Cardiol. 2018;268:166-9.

116. Van Tassell BW, Trankle CR, Canada JM, Carbone S, Buckley L, Kadariya D, et al. IL-1 Blockade in patients with heart failure with preserved ejection fraction. Circ Heart Fail. 2018;11(8):e005036.
117. Shah SJ, Voors AA, McMurray JJV, Kitzman DW, Viethen $\mathrm{T}$, Bomfim Wirtz A, et al. Effect of neladenoson bialanate on exercise capacity among patients with heart failure with preserved ejection fraction: a randomized clinical trial. JAMA. 2019;321(21):2101-12.

118. Maurer MS, Teruya S, Chakraborty B, Helmke S, Mancini D. Treating anemia in older adults with heart failure with a preserved ejection fraction with epoetin alfa: single-blind randomized clinical trial of safety and efficacy. Circ Heart Fail. 2013;6(2):254-63.

119. Kaptein YE, Karagodin I, Zuo H, Lu Y, Zhang J, Kaptein JS, et al. Identifying phenogroups in patients with subclinical diastolic dysfunction using unsupervised statistical learning. BMC Cardiovasc Disord. 2020;20(1):367.

120. Cohen JB, Schrauben SJ, Zhao L, Basso MD, Cvijic ME, Li Z, et al. Clinical phenogroups in heart failure with preserved ejection fraction: detailed phenotypes, prognosis, and response to spironolactone. JACC Heart Fail. 2020;8(3):172-84.

121. Volpe M, Patrono C. The EMPEROR-preserved study: end of the search for the "Phoenix" or beginning of a new season for trials in heart failure with preserved ejection fraction. Eur Heart J. 2021;42(45):4621-3.

Publisher's Note Springer Nature remains neutral with regard to jurisdictional claims in published maps and institutional affiliations. 